\title{
Application Level of Internal Audit Systems applied at Government Hospitals in North of Jordan
}

\author{
Hasan Salih Suliman Al-Qudah ${ }^{1}$ \\ ${ }^{1}$ Department of Health \& Hospital Service Management, College of Business-Rabigh Branch, King Abdul-Aziz \\ University, Kingdome of Saudi Arabia \\ Correspondence: Hasan Salih Suliman Al-Qudah, Department of Health \& Hospital Service Management, \\ College of Business-Rabigh Branch, King Abdul-Aziz University, Kingdome of Saudi Arabia. E-mail: \\ hasancare@gmail.com
}

Received: September 22, 2016

Accepted: October 21, 2016

Online Published: November 20, 2016

doi:10.5539/ijbm.v11n12p187

URL: http://dx.doi.org/10.5539/ijbm.v11n12p187

\begin{abstract}
This research aims to find out "Application level of internal audit systems applied at private hospitals at north of Jordan". The study population comprised of all employees who are working at government hospitals at North of Jordan. a questionnaire was distributed to (291) employees in Government hospitals as research sample, but excluded (10) questionnaires for non-suitability to statistical analysis, the analyze data using statistical system (SPSS), one and most prominent results of the study as indicated the importance of Proper auditing shall be made out to convince employees that performance set fair standards as they shall be conviction that Auditing is a tool to measure their progress while performing their duties and recommended The need for those hospitals to acquisition most advanced programs of information technologies system in order to improve auditing processing system effectively and efficiently.
\end{abstract}

Keywords: auditing, system, hospital

\section{Introduction}

Internal audit has grown up to meet the needs of the organization surrounding environment. Since ancient times man had exercise various economic activities in agriculture, industry or trade by hiring all means to succeed of man's workflow of business, or by monitoring and control employees implementation engagements of these actions, it was applied the practice to the concept of the audit without a theoretical framework to enable regulating internal auditing practice.

Internal auditing process is considered to be as part of administrative structure run with organization operational procedures at all government units. Auditing is an integrated system within operational processes of any organization targeted to achieve goals or to carry out censorship mechanisms, censorship itself is the way to achieve organization goals but not an end in itself.

The need for auditing is to review all organizational operational aspects; the need to a qualified internal audit was to maintain its eligible to perform functions in scientifically and professional manner. This need was emerged to access among internal auditing professional, to meet with confluence of those knowledgeable experts who are designed to meet together as for ideas exchange (Putin, 2005).

With the exposure needs for internal audit recognition, some organization departments fails to develop a solid system of internal audit mechanism more effectively, to help to contribute to the organization's implementation deferent policies and objectives with high achievements.

Administration shall not be designed as a reference to internal audit system, nevertheless but it shall provide appropriate confirmation, by which financial statements shall be prepared in a fair and justified manners. The internal auditing system then shall be designed by facilitating considering the costs and benefits of internal audit system and to keep in mind the logics of different interior auditing system of any firms, depending on the nature activity of surrounding environment (Sweilem, 2009).

Internal audit function includes examining and evaluating all financial and administrative processes to ensure that they are implemented in accordance t plans and policies previously drawn by organization, the internal auditor is an organization employee functioning that associated within organizational structure of auditing 
committee aims to achieve all achieved tasks before and after accomplishment from top management and be responsible for auditing committee without attached to any general manager of organization down of any structure (Momani, 2009).

Internal auditing can be defined as "the quest to reach objectively and effectively with any assurance consultant, as it adds value to develop certain processes to achieve the organization objectives, through structural effectiveness approach to assesse, develop all management activities or to supervising of institutional control. (Jumaah, 2005).

Internal auditors appraise businesses by monitored, evaluated, to extent how risks was eliminated and being managed and minimized to maximum. They can provide a consulting service, advising top management on how to improve systems and processes. The scope and nature of audits can vary significantly but its main priority to make sure that any issues that affect the survival and prosperity of the business can be dealt with. The work of an internal auditor differs to that of external auditors as they look at more to financial or accounting risks. They can consider factors such as reputation, growth, environmental impact, and employee's ethics. Their work helps top management by providing them facts and evidence to stakeholders on how they can have deep insightful in all levels by guiding and enlighten them on the right direction and by managing the business effectively. (Makhlouf, 2007).

Abu-Ghazaleh (2001) has summarized auditing function as following:

A- To provide a reliable periodically data information;

B- To reduce external audit costs;

C- The internal audit department shall have a wide knowledge of organization functions relating to regulations procedures;

D- Internal audit can indicate to what extent of organization to achieve organization goals or objectives, this helps to correct any deviation path while organization acts to assist in adoption to any planning or any decision-making policies (Abu-Ghazaleh, 2001).

\subsection{Problem \& Questions of the Study}

Internal auditing is considered to be as one and most important elements upon which auditor resurrection during auditing review, auditing is the second criterion at any working standards.

The application of internal auditing methods will lead to immune of any organization from falling into any cases of fraud or manipulation, embezzlement, but however, there must be a regulator of any process; this is what a systems analyzing can do, but many of them lack knowledge or competence in order to carry out any fullest efficiency and effectiveness; organizations which has not any in-depth analyzing systems they will suffer naturally from a lot of fraud and manipulation and embezzlement operations, so it is also difficult for any with absence of auditing system will be hard to detect any of these cases.

\subsection{The Study Problem Projecting shall Answer the Following Questions}

1- What's the level of internal audit application systems among employees in government hospitals north of Jordan?

2- There are significant differences in internal effective auditing system due to educational qualification variables?

3- There are significant differences in internal effective auditing system due to demographic variables (Gender Experience)?

\subsection{Study Objectives \& Importance}

The primary objective of this study was to determine and try to envisage internal audit application systems by formulating a broad planning and development framework setting out guidelines and standards for more effective and comprehensive understanding of the study "Application level of internal audit systems applied at some government hospitals north of Jordan", relating to employment gender for both male and female careers, the second objective will focus to determine and compare level of educational qualification development of the study sample administrators, and current employees in these hospitals.

\subsection{Definitions of Terminologies}

Internal Audit: Internal auditing is an independent, objective assurance and consulting activity designed to add value and improve an organization's operations. It helps an organization accomplish its objectives by bringing a 
systematic, disciplined approach to evaluate and improve the effectiveness of risk management, control, and governance processes. (http://www.theiia.org/)

Hospital: is a health care institution providing patient treatment by specialized staff and equipment. The best-known type of hospital is the general hospital, which has an emergency department. (https://en.wikipedia.org/wiki/Hospital)

\section{Theoretical Studies}

A Study of (Kirzan, 2010) has on her research stressed on "The extent to which senior management in Syrian banks of the importance of internal audit in increasing the value of banking operations and improve." As it aimed to identify the perceptions of senior management in the Syrian banks of the importance of internal audit in increasing the value of banking operations and improved by the internal audit's contribution are as follows:

1)-Assess the efficiency and effectiveness of the internal auditing in banks.

2)-Evaluate of risk management in banks, like corporate governance banks.

The study findings were that senior management was aware of internal audit importance in both Syrian public-private banks, in increasing and improvement the value of banking operations.

Another study done by Robert (2009) has pointed out in his study "Identification audit system for hospitals to control costs and improve quality: the experience of Maryland," as to recognizing the essential of audit system in hospitals in Maryland state USA, it demonstrated the legitimization of international laws and regulations to be adopted widely, and concluded on concentrating on existence of quality programs to be applied in the health system, as price of costing is one of the successful programs in the United States, the study stressed on the need to take lessons from other countries adopting auditing system, it recommended the need to do more health reforms in future.

Study of Vladimir Bolek et al. (2015) focused on "Process modeling of internal audit in healthcare center" as they compare an audit of domestic and foreign authors. The authors determine the elemental substance of the definition, namely that it is a systematic evaluation of the audited object based on pre-defined rules, norms and standards for the area. The fundamental aim of the scientific paper is to propose and then optimize the model of the process of internal audit on the quality of services in a health facility. The process model of internal audit has been created by the method-Event-driven Process Chain by the help of the modeling tool. The main objective of the scientific paper has been achieved by implementing a number of scientific methods. As a result, a model for internal audits in the health facility has been created and segmented into three areas and subsequently optimized. The audit activities are the main diagnostic tool for top management and act as evaluation and feedback that provides information about the status of the quality of medical equipment and processes taking place in it. Audits represent an independent source of information and cover all the processes that make up a quality management system. Nowadays, the auditing process is considered the largest and most widely used management tool for determining the level of quality management system.

As for Carlos A. Bana e Costa, (2012) on their research paper entitled "A multi-criteria model for auditing a Predictive Maintenance Programme" pointed out that auditing tools can play a key role in the continuous improvement of maintenance policies, in particular, to enhance predictive maintenance (PM). This paper proposes a multi-criteria model for auditing a Predictive Maintenance Programme (PMP) developed and implemented in the General Hospital of Ciudad Real (GHCR) in Spain. The model has a two-level structure, with top level auditing areas specified by second level auditing criteria on which the performance of the PMP should be appraised. This structure resulted from the analysis and discussion of an internal questionnaire to the management, the technical and consulting staff of GHCR. This also guided the association of a performance scale with each criterion, describing several reference levels of accomplishment. Using the MACBETH (Measuring Attractiveness by a Categorical Based Evaluation Technique) approach, a hierarchical additive value model was constructed, with criteria weights and value scales derived from staff judgments of comparison of different reference levels and profiles of performance. This model enables managers to measure the performance of the PMP and its added value for the hospital, not only against each audit criterion individually but also on each area and in overall terms. Integrated into a management "tableau de bord", the model outputs permit the identification of PMP deficiencies requiring urgent intervention and corrective measures for its continuous improvement.

Mahmoud Al-Akra et al. (2016) clarified with their entitled article entitled "Internal auditing in the Middle East and North Africa: A literature review "that Institute of Internal Auditors (IIA) has conducted several surveys to understand the development of the internal auditing (IA) profession worldwide. In its latest survey, the Middle 
East and North Africa (MENA) region was expected to experience the most significant changes in the regulation of internal auditing (IIA, 2010). This study reviews the MENA region literature dealing with recent regulatory reforms in internal auditing, focusing on independence and objectivity, assurance versus consulting services, and the IA role in consulting activities. We find that while the majority of the region has introduced reforms to the IA function, more needs to be done to (1) ensure independence and objectivity; and (2) involve IA in consulting services, particularly with respect to risk management, control, and governance. This review and its findings are timely given the vast advances the IA profession is witnessing and has implications for both the IIA and MENA countries' regulators. The study also hopes to motivate further research in this region.

A study of Tatiana Danescu et al. (2015) has demonstrated with their entitle paper "The Valances of the Internal Audit in Relationship with the Internal Control" that in a market which is competitive and affected by systemic risks the endanger of good, secure and continuous functioning of activities, entities generate behaviors which mark rights and obligations that highlight the necessity of adequate leadership and control systems, through which a rigorous management of the risks that could affect the targeted objectives is insured. Actually, these objectives are facilitated by the existence of an independent function that evaluates the processes of governance, internal control, and risk management. From this perspective, the internal audit, which is an objective and independent function, through its formulated opinions and recommendations, it supplies reasonable insurances to the management, which gives it an essential role in the frame of the analyzed relationship. This study proposes testing this hypothesis so that the carried research has focused on the identification of new valences through which the internal audit could contribute to the improvement of the corporate governance.

But while the study of Alexandra Narcisa and others (2015) has shown the important role of their paper "The Impact and Results of the Internal Audit Activity Exercised in the Public Sector in Romania" of what should they do to get favorable and measurable result of the public internal audit activity? An overall evaluation of the internal audit activity exercised in recent years in the public sector in Romania in order to identify the reasons for malfunctioning and finding possible solutions that lead to more efficient internal audit activity. Regarding this, the research disseminates information obtained from public internal audit reports; it examines audit risk, organizational framework, attributes of the audited entity and highlights the interaction of these factors that influence differently the effectiveness of internal audit. Following a thorough search, we can say that the impact of internal audit in the public sector is strongly influenced by the quality of internal audit mission and also by early and accurate identification of the risks while organizational framework and audit attributes have not a severe impact on audit efficiency.

As for Siti Zabedah Saidin (2014) at his distinctive study entitled "Work Reduced the External Audit Cost and External Audit Work" he further describe that the main objective of this study is to examine whether reliance by the external auditors on the internal auditors' work lead to a reduction in the external audit cost and external audit work. Two different questionnaire surveys were sent to 387 head of internal auditors and 142 external auditors of the English local authorities, yielding a response rate of $43.9 \%$ and $45.0 \%$ respectively. Findings of the study show that the external auditors in English local authorities perceived that their reliance on internal audit work has no effect on the external audit fees or on the external audit work. Internal auditors in English local authorities perceived the external auditors' reliance on their work has no effect on the external audit fees but has reduced the extent of the external audit work. To conclude, the reliance on internal audit work in the local authorities in England does not have much impact on reducing external audit fees and external audit work. However, it does help to minimize increases in external audit fees.

Dessalegn Getie (2014) interpreted at his valuable study "How can we explain internal auditing?. The inadequacy of agency theory and a labor process alternative "as he draws on labor process theory (LPT) to explain how capitalism creates conditions that give rise to a demand for internal auditing. Internal auditing developed from the metamorphosis of capitalism during the twentieth century, when capital gradually succeeded in institutionalizing structural control of labor processes to address the problem of control in inherently antagonistic capital-labor relationships. In this control context employee, management, and the board of directors is responsible for achieving the required rate of return on capital. With the premise that the literature has not adequately theorized the role of internal auditing in this context, this paper proposes an initial theorization of the role of internal auditing as a mechanism employed by management and the board of directors to control the labor process in the generation and realization of surplus value. Internal audit's assurance services to execute business activities according to management's conceptions, and its advisory services to enhance efficiency and effectiveness, are interpreted within the firm's overarching goal of maximizing the rate of return on capital employed. Future research agenda and methodological considerations are discussed. 
Vladimír Bolek et al. (2015) in the entitled research "Process modeling of internal audit in healthcare center" discussed with length and clarity in their entitled research paper, that they compare the definitions of an audit of domestic and foreign authors. The authors determine the elemental substance of the definition, namely that it is a systematic evaluation of the audited object based on pre-defined rules, norms and standards for the area. The fundamental aim of the scientific paper is to propose and then optimize the model of the process of internal audit on the quality of services in a health facility. The process model of internal audit has been created by the method .Event-driven Process Chain by the help of the modeling tool - ARIS Express. The main objective of the scientific paper has been achieved by implementing a number of scientific methods. As a result, a model for internal audits in the health facility has been created and segmented into three areas and subsequently optimized. The audit activities are the main diagnostic tool for top management and act as evaluation and feedback that provides information about the status of the quality of medical equipment and processes taking place in it. Audits represent an independent source of information and cover all the processes that make up a quality management system. Nowadays, the auditing process is considered the largest and most widely used management tool for determining the level of quality management system.

H. D. Kuna and other researchers (2014) in their research work entitled "Outlier detection in audit logs for application systems" tried to clarify outlier mechanism of the entitled paper to defined as an observation that is significantly different from the other data in its set. An auditor will employ many techniques, processes, and tools to identify these entries, and data mining is one such medium through which the auditor can analyze information. The enormous amount of information contained within transactional processing systems' $\operatorname{logs}$ means that auditors must employ automated systems for anomalous data detection. Several data mining algorithms have been tested, especially those that deal specifically with classification and outlier detection. A group of these previously described algorithms was selected for use in designing and developing a process to assist the auditor in anomalous data detection within audit logs. We have been successful in creating and ratifying an outlier detection process that works in the alphanumeric fields of the audit logs from an information system, thus constituting a useful tool for system auditors performing data analysis tasks

Victor Munteanua and Zahariab (2014) in their entitled paper " Current Trends in Internal Audit" has defined that internal audit is considered a profession that has emerged over the years, always seeking to meet the changing needs of their organizations. The internal audit focused on accounting problems at its beginnings, but now it has become a powerful tool to detect the main risks of organizations. As function, internal audit is a relatively recent occurrence, located, according to some authors, during the 1929 economic crisis in the USA.

While Maria Caratas and Elena Spatariu (2014) in research paper focused on "Contemporary Approaches in Internal Audit" as they explain the role of internal audit in the contemporary life of a company. Internal audit function plays a major role in the enterprise, carrying on control in the financial field and all others settled by management, safeguarding the corporate assets and ensuring the security of accurate records. Between internal audit and the prosperity of a company, there is a strong link which leads to increase the value of the company and achieve its objectives. The relevance of internal audit reporting is given also by adapting its function to the changing expectations and its alignment to fraud prevention policies, aside with risk evaluation and improvement of control strategies.

Abdulaziz Alzeban and David Gwilliam (2014) entitled "Factors affecting the internal audit effectiveness: A survey of the Saudi public sector". This study assesses factors influencing internal audit effectiveness (IAE) in Saudi Arabia. Data were obtained from 203 managers and 239 internal auditors from 79 Saudi Arabian public sector organizations. Multiple regression analysis examines the association between IAE and five principal factors. Results suggest that management support for IAE drives perceived effectiveness of the internal audit function from both management's and the internal auditors' perspective. Management support is linked to hiring trained and experienced staff, providing sufficient resources, enhancing the relationship with external auditors, and having an independent internal audit department. Saudi Arabia is representative of many developed and developing environments and its recent tradition of governance and audit is mirrored in countries worldwide. Moreover, its specific cultural traditions involving clan and tribal allegiances, and pervasive and core religious beliefs, characterize the GCC countries, the Arab World generally, and indeed, many other developing countries, irrespective of wealth. Thus, links between management support and internal audit effectiveness are likely generalizable beyond the Saudi public sector context.

\section{Research Methodology}

Descriptive and analytical study approach were used to analyze and interpret all statistical treatment of variables and data collection, interpretation of the study has reached some results As for the research, the sample study 
was 1200 of those working in government hospitals north of Jordan. Questionnaires optimize 291 were distributed, and 10 was excluded for its unsuitability to statistical analysis, so was suitable for statistical analysis, the study has implied SPSS statistical analysis system on data. Lastly Cronbach's alpha Test was also used to measure study stability of measuring instrument as value alpha $\alpha=95.14 \%$ which is an excellent ratio being higher than 60\%. As acceptable, Independent Samples t-test was also used to figure out differences with respect to variable gender for male, female. The variance test One Way ANOVA, used to determine differences in terms of experience variable

\subsection{Research Sample Study}

Table 1. Frequencies percentages for gender variable

\begin{tabular}{lll}
\hline Gender & Repetition & Percentage \\
\hline Male & 201 & $\% 71.53$ \\
Female & 80 & $\% 28.47$ \\
Total & 281 & $100.0 \%$ \\
\hline
\end{tabular}

As can be illustrated on table 1 indicated that male's forms $71.53 \%$ of study sample, while female forms were $28.47 \%$ of study sample, its there for shows that men's has more contribution in the results of study as it was more highest from women's responses.

Table 2. Research sample distribution by qualification variable

\begin{tabular}{lll}
\hline Education Level & Repetition & Percentage \\
\hline Diploma Or less & 70 & $\% 24.91$ \\
Bachelor & 200 & $\% 71.18$ \\
Higher Education & 11 & $\% 3.91$ \\
Total & 281 & $100.0 \%$ \\
\hline
\end{tabular}

As seen also from table 2 data shows percentage of those who hold a diploma was less percentage at $24.91 \%$, while those who hold first university degree bachelor's was at $71.18 \%$. As for those respondents with higher education has $3.91 \%$ percentage

Table 3. Arithmetic average consent degree

\begin{tabular}{ll}
\hline Arithmetic Average & Consent Degree \\
\hline $2.33-1$ & Low \\
$3.67-2.34$ & Middle \\
$5-3.68$ & Higher \\
\hline
\end{tabular}

\section{Discussion of Results}

The first question: What is the level of application of internal audit in private hospitals in Amman, Jordan systems?

In order to answer this question was used descriptive statistics to extract the arithmetic mean deviation of the questions the study was summarized in the following table. 
Table 4. Arithmetic mean \& standard deviation of questionnaire paragraphs

\begin{tabular}{|c|c|c|c|c|c|}
\hline No. & Paragraph & $\begin{array}{l}\text { Arithmetic } \\
\text { Mean }\end{array}$ & $\begin{array}{l}\text { Average } \\
\text { Measurement tool }\end{array}$ & $\begin{array}{l}\text { Standard } \\
\text { Deviation } \\
\end{array}$ & $\begin{array}{l}\text { Degree } \\
\text { Significance } \\
\end{array}$ \\
\hline 1 & $\begin{array}{l}\text { The Internal Audit System identifies inappropriate use of } \\
\text { procedures and practices. }\end{array}$ & 3.43 & 3 & 0.751 & Middle \\
\hline 2 & $\begin{array}{l}\text { The information systems Performing business according } \\
\text { to certain procedures standards for. }\end{array}$ & 3.12 & 3 & 1.23 & Middle \\
\hline 3 & $\begin{array}{l}\text { There is continuous technological improvement conducted } \\
\text { oversight process. }\end{array}$ & 2.76 & 3 & 0.77 & Middle \\
\hline 4 & $\begin{array}{l}\text { There is use of uniform auditing system leads to errors } \\
\text { reduce that can occur. }\end{array}$ & 3.77 & 3 & 1.23 & Higher \\
\hline 5 & $\begin{array}{l}\text { There are unified information system in field of auditing } \\
\text { to ensure greater accuracy and reliability by Internal Audit } \\
\text { Department. }\end{array}$ & 3.84 & 3 & 1.66 & Higher \\
\hline 6 & $\begin{array}{l}\text { The use of a uniform system in the area of auditing } \\
\text { facilitates process of internal audit procedure. }\end{array}$ & 3.71 & 3 & 1.51 & Higher \\
\hline 7 & $\begin{array}{l}\text { The use of a uniform system in the audit limiting affects } \\
\text { price factors and services. }\end{array}$ & 3.82 & 3 & 1.61 & Higher \\
\hline 8 & The hospital uses uniform and effective control system. & 3.25 & 3 & 0.72 & Middle \\
\hline 9 & $\begin{array}{l}\text { The use of recognized auditing systems provides effective } \\
\text { economic use of resources. }\end{array}$ & 3.85 & 3 & 1.32 & Higher \\
\hline 10 & $\begin{array}{l}\text { The worker enjoys appropriate level to tasks required of } \\
\text { them. }\end{array}$ & 3.44 & 3 & 1.51 & Middle \\
\hline 11 & $\begin{array}{l}\text { The devices used provide desired objectives as appropriate } \\
\text { to information system. }\end{array}$ & 3.25 & 3 & 0.83 & Middle \\
\hline 12 & $\begin{array}{l}\text { The qualified workers in information systems } \\
\text { commensurate according to nature of working assigned to } \\
\text { them. }\end{array}$ & 3.21 & 3 & 1.42 & Middle \\
\hline \multicolumn{2}{|c|}{ Degree possession of a whole } & 1.21 & & 3.45 & Middle \\
\hline
\end{tabular}

Table 4 indicate that the differentiation arithmetic mean of the study sample respondents on the auditing level application was between 2.76-3.84, as it also clear of table 4 shown, that the overall average about respondents from the study main dimensions, was 3.34, due to many reasons out of them that the average measurement tool was 3 , with middle degree, while average standard deviation stood at 1.1415. It is also clear from above table that the trends of the study sample, was positive about all paragraphs except for paragraph 3 , which indicates about continuous adapting of latest auditing procedures or technology can help to improve total organizational process, due to average arithmetic to this particular paragraph was 2.76 . it means that some hospitals do not provide any advance technologies in terms of how can improve and effect highly to how auditing process can have that effect of improvement, through this discussion work must continue developing at all means of works, by using the latest modern technologies to develop process of auditing measuring which can effect highly the procedures of auditing process. As for paragraph 5, hospitals using unified information system, auditing can ensure greater accuracy and reliability by establishing of Internal Audit Department, this has received highest answer from sample study, of arithmetic average mean at 3.84.

Second question:" Are there significant differences at internal audit systems level by employees in Government hospital at North of Jordan", due to (Gender male, female)?

In order to identify to extend the possibility of acceptance for this question, Independent Samples t-test, was conducting to analyze (c). Table 5 shows that.

Table 5. Test results (Independent samples t-test) for the first hypothesis

\begin{tabular}{lllll}
\hline Gender & Arithmetic Mean & Standard Deviation & t Value & Significance Level \\
\hline Male & 3.21 & 0.41 & \multirow{2}{*}{0.215} & \multirow{2}{*}{0.851} \\
Female & 3.33 & 0.32 & & \\
\hline
\end{tabular}


As for table 5 indicated that the arithmetic mean for males was 3.21 , with a standard deviation of 0.41 , while female arithmetic mean was 3.33 , with a standard deviation of 0.32 , which indicates making that the statistical significance differences between both M\&F appears, as the result among males was higher than of females. The value of (t) was 0.215 , which is not statistically significant at the level at 0.851 , while this level of significance level was above than 0.05 . The result indicates that there were no statistically significant differences at application internal audit level systems among stuff working on these government hospitals, due to Gender variable.

Third question: Is there significant differences at the application level of internal audit systems by staff working at a government hospital in north of Jordan, attributed Academic Expertise? In order to analyze the credibility of this question if we can accept this hypothesis, the researcher conducting one-way analysis.

Table 6. Results of the one-way analysis of variance (One-Way ANOVA) for the second hypothesis

\begin{tabular}{|c|c|c|c|c|c|c|c|}
\hline Source of Variation & $\begin{array}{l}\text { Degree of } \\
\text { Freedom }\end{array}$ & $\begin{array}{l}\text { Total } \\
\text { Boxes }\end{array}$ & Differences & $\begin{array}{l}\text { Average } \\
\text { Boxes }\end{array}$ & Differences & F Value & $\begin{array}{l}\text { The level of } \\
\text { Significance }\end{array}$ \\
\hline Between Groups & 1 & 1.021 & & 0.502 & & & \\
\hline Within Groups & 279 & 2.751 & & 0.169 & & 3.521 & 0.001 \\
\hline Total & 280 & 3.772 & & & & & \\
\hline
\end{tabular}

As seen from table 6 , the study relies to test the variance by using (One-Way ANOVA), the F value was 3.521, which is statistically significant at 0.001 level, since this level is less significant than 0.05 . The result then indicates that there are significance statistical differences at $(\alpha \leq 0.05)$ for level of the application of internal audit systems by staff working at government hospitals at north of Jordan; which was attributed to employees Academic expertise.

In order to determine the statistical differences direction were tested using Shave (Schaffer) dimensionless comparisons, as shown in the Table 7.

Table 7. Results Shave comparisons posterior manner (Schaffe) to detect differences source in study sample with respect to response experience variable

\begin{tabular}{|c|c|c|c|c|}
\hline Dimension & Experience & Number & $\mathrm{t}$ value & significance level \\
\hline \multirow{5}{*}{$\begin{array}{l}\text { The level of internal audit } \\
\text { application systems at private } \\
\text { hospitals in Amman. }\end{array}$} & $1-5$ Yrs & 70 & 0.21 & 0.03 \\
\hline & $6-10 \mathrm{Yrs}$ & 120 & 0.61 & 0.05 \\
\hline & $11-16 \mathrm{Yrs}$ & 60 & 0.77 & 0.00 \\
\hline & More than 17 & 31 & 0.88 & 0.00 \\
\hline & Years & & & \\
\hline
\end{tabular}

Table 7 shows that there is significant differences at $(\alpha \leq 0.05)$ in the sample responding about the level of internal audit application systems by emplyees at government hospital north of Jordan; due to academic experience, but it was in favor among employees having experienced from 11-16 years, or over 17 years, when compared with those who have 1-5 years of experience, or to those who have 6-10 years, this indicates that for those with high expertise can be capable to use efficient application of internal audit systems better than others with less experience, this is due to bulk and huge years of field experience they obtain during the course of action, also due to academic wide knowledge they have, compared with less experienced inventory, which obviously would effects improve total all of hospital performance.

\section{Results}

The study has reached many conclusions and results as following:

1- The study has reached many results that there were no significant statistically differences at the level of internal audit systems application in at government hospital in North of Jordan, due to Gender variable. The result then is that there are statistical significance differences at $(\alpha \leq 0.05)$ to the level of internal audit systems application by staff working at a government hospital in North of Jordan; attributed to Academic Expertise.

2- Proper auditing shall be made out to convince employees that performance set fair standards as they shall be conviction that Auditing is a tool to measure their progress while performing their duties. 


\section{Conclusion}

Auditing focuses on improving their performance and increase their productivity and efficiency, but it is unfortunate this positive concept of management is often not clear to those in charge for the same censorship, if they looked upon as a means of control, domination or oppression. Internal Auditing may extend offices establishment of any complaints and grievances from which to measure any weaknesses or shortcomings in administrative aspects of the business that can be processed in a timely manner.

\section{Recommendations}

1). The need to have more staff involvement in majority of government hospital north of Jordan, with many different training courses specialized and focused to many internal audit areas, for both financial or administrative employees operations at all levels of hospital organization.

2). The need for those hospitals to acquisition most advanced programs of information technologies system in order to improve auditing processing system effectively and efficiently.

3). There is a need for new research in the field of internal auditing procedure.

4). Disseminate the results present study on to other relevant sectors.

5). Hospital shall reviewed hospital by applying the employees with latest technical tools about auditing training courses.

\section{References}

Abdul-Aziz, A., \& David, G. (2014). Factors affecting the internal audit effectiveness: A survey of the Saudi public sector. Journal of International Accounting, Auditing and Taxation, 23(2), 74-86. http://dx.doi.org/10.1016/j.intaccaudtax.2014.06.001

Abu, G. M. (2001). Auditing of modern accounts. Dar AlSafa for printing publishing and distribution. Amman, Jordan .

Al Momani, M. A. (2009). Role of boards of directors in Jordanian companies enhancing effectiveness audit committees, (Case Study). University of Damascus for Economic and Legal Science Journal, 25(1), 25-55.

Alexandra, N. C., Elena, H., \& Ana, M. Z. (2015). The Impact and Results of the Internal Audit Activity Exercised in the Public Sector in Romania. Procedia Economics and Finance, 32, 394-399. http://dx.doi.org/10.1016/S2212-5671(15)01409-4

Carlos, A. B. C., María, C. C., \& Mónica, D. O. (2012). A multi-criteria model for auditing a Predictive Maintenance Programme. European Journal of Operational Research, 217(2), 381-393. http://dx.doi.org/10.1016/j.ejor.2011.09.019

Dessalegn, G. M. (2014). How can we explain internal auditing? The inadequacy of agency theory and a labor process alternative. Critical Perspectives on Accounting, 25(8), 771-782. http://dx.doi.org/10.1016/j.cpa.2014.01.003

Gomaah, A. F. (2005). Entrance to modern auditing. Dar AlSfaa for Publishing and Distribution, Amman, Jordan.

Kirzan, F. H. (2010). Extent of top management at Syrian banks of internal audit importance in increasing value of improving banking operations. Unpublished Master Thesis, University of Damascus. Syria.

Kuna, H. D., García-Martinez, R., \& Villatoro, F. R. (2014). Outlier detection in audit logs for application systems. Information Systems, 44, 22-33. http://dx.doi.org/10.1016/j.is.2014.03.001

Mahmoud, A. A., Waleed, A. Q., \& Mamun, B. (2016). Internal auditing in the Middle East and North Africa: A literature review. Journal of International Accounting, Auditing and Taxation, 26, 13-27. http://dx.doi.org/10.1016/j.intaccaudtax.2016.02.004

Makhlouf, A. (2007). Internal audit in light of international standards for internal auditing reviewing at Jordanian commercial banks. unpublished Master Thesis, Faculty of economics and management science, University of Algiers, Algeria.

Maria, A. C., \& Elena, C. S. (2014). Contemporary Approaches in Internal Audit. Procedia Economics and Finance, 15, 530-537. http://dx.doi.org/10.1016/S2212-5671(14)00503-6

Putin, M. (2005). Review and monitor the accounts of theory to practice. Office university publications Press. Unpublished Master theses. Algeria. 
Robert, M. (2009). Setting Hospital Rates to Control Costs and Boost Quality: The Maryland Experience. Health Affairs, 28(5), 1395-1405. http://dx.doi.org/10.1377/hlthaff.28.5.1395

Siti, Z. S. (2014). Does Reliance on Internal Auditors' Work Reduced the External Audit Cost and External Audit Work? Procedia-Social and Behavioral Sciences, 164(31), 641-646.

Sweilem, A., \& Atallah A. (2009). Internal Audit and Audit in the IT environment. Dar Al-Raya for publication and distribution, Amman, Jordan.

Tatiana, D. A., Mihaela, P. B., \& Roxana, D. P. (2015). The Valances of the Internal Audit in Relationship with the Internal Control-Corporate Governance. Procedia Economics and Finance, 26, 960-966. http://dx.doi.org/10.1016/S2212-5671(15)00915-6

Victor, M., \& Dragos, L. Z. (2014). Current Trends in Internal Audit. Social and Behavioral Sciences, 116, 2239-2242.

Vladimír, B., Jana, F., Iveta, O., \& Jana, M. (2015). Process modeling of internal audit in healthcare center. Kontakt, 17(3), 154-162. http://dx.doi.org/10.1016/j.kontakt.2015.08.006

\section{Copyrights}

Copyright for this article is retained by the author(s), with first publication rights granted to the journal.

This is an open-access article distributed under the terms and conditions of the Creative Commons Attribution license (http://creativecommons.org/licenses/by/4.0/). 